\title{
NÉCROLOGIE
}

\section{GEORGES YVER}

\section{I870-1961}

Les jeunes historiens qui travaillent autour de moi et m'écoutent à l'occasion, au Collège de France ou à l'École des Hautes Études, auront bien connu Georges Yver durant ces quinze dernières années. Il était leur ami. Plus encore, nous étions ses amis; nous lui donnions la seule raison qu'il avait encore de sortir d'une vie austère et d'échapper à des ennuis et à des tourments sans nombre. Après un long enseignement à la Faculté des Lettres d'Alger, puis une halte à Nice pendant la Seconde Guerre Mondiale, il avait dû tout vendre ou mettre au garde-meuble, se séparer d'une magnifique installation, puis faire hospitaliser sa femme dans une maison de santé ; et il était venu vivre seul à Paris, à soixantequinze ans passés, dans une simple chambre d'hôtel du quartier de la gare Saint-Lazare, au milieu du bruit et du mouvement qu'il aimait et qui lui permettaient, sans doute, d'oublier sa solitude. Une vie difficile. Il l'accepta avec ce courage discret qui fut toujours le sien.

Dix années durant, l'amitié l'amena, chaque mercredi et chaque samedi, à mes cours du Collège : ils étaient sa sortie, sa prise de contact avec le monde des vivants. Ensuite, nous retournions à pied jusqu'à la Cité Universitaire, d'où il regagnait alors en métro son lointain hôtel.

L'amitié, aussi, l'avait entraîné, en 1958, à faire en ma compagnie ('e voyage jusqu'à Venise qui fut peut-être sa dernière grande joie.

Nos amis communs peuvent en témoigner : il avait non seulement conservé une vigueur corporelle miraculeuse, mais trouvé une seconde jeunesse de l'esprit; il avait cet élan, cette intelligence hors de pair qui avaient fait de lui, en 1902, avec sa thèse sur Le commerce et les marchands dans l'Italie Méridionale au XIII ${ }^{\mathrm{e}}$ et au XIVe siecle, sans qu'il le sût, ou que la Sorbonne d'alors le reconnût comme tel, le premier des historiens économistes de son temps, peut-être le seul.

Sa nomination à Alger, en 1904, l'avait amené dans un pays qu'il allait passionnément aimer, mais elle l'avait aussi détourné de sa vraie vocation et jeté en pleine histoire corrosive, celle de la conquete de l'Algérie par les Français, où tout était à élaborer et d'abord la trame des événements, le rôle des individus, la place des institutions. Il fut soumis 
à de petites tâches ingrates, qu'il fit trop bien, avec une conscience méticuleuse.

Jusqu'au dernier jour, il aura travaillé, publié ', lu avec passion ; il aura raconté d'exquis souvenirs sur le Paris de sa jeunesse, sur l'École Normale où il avait été l'ami et le compagnon de Georges Fedel, de Zimmerman, de René Lespès, d'Édouard Herriot, sur l'Algérie si proche et si lointaine... Nul, par contre, ne l'entendit parler de ses propres succès, jadis, au Concours général, à l'entrée de l'Ecole, à l'agrégation d'histoire. Pour y penser, il était bien trop préoccupé de faire l'éloge des autres et surtout de ses maitres : Vidal de la Blache, G. Monod, plus encore Émile Bourgeois, à l'égard de qui, comme l'auteur de ces lignes, il avait conservé un attachement indéfectible.

Comment dire la dévotion que je lui portais, que nous lui portions ? Il m'avait accueilli, il y a plus de quarante ans, à Alger, avec tant de chaleur et d'amitié 1 Avant que Lucien Febvre n'intervienne dans ma vie, il a été le meilleur de mes conseillers et de mes maîtres. C'est grâce à lui, en premier lieu, qu'un beau jour je me suis décidé à saisir pour ellemême, et non de biais, la vie entière de la Méditerranée. J'hésitais devant son immensité. Il eut l'audace qui me manquait.

Avec Georges Yver se clôt pour la Faculté des Lettres d'Alger, que j'ai admirée au temps de ma jeunesse, aussi belle, sinon aussi vantée, que celle de Strasbourg, le cortège de tous ceux que nous y avons connus ou aimés : Eugène Albertini, Émile-Félix Gautier, Louis Leschi, Louis Gernet, Jean Alazard, Pierre Martino...

Fernand Braudel.

1. Dans la * Collection de documents inédits sur l'histoire de l'Algérie après 1830 ", publiée par le Gouvernement Général, il a fait paraître d'importants volumes : Correspondance du Capitaine Daumas, consul d Mascara (1837-1839), 1912 ; Documents relatifs au trailé de la Tafna (1837), 1924; Correspondance du Général Damrémont, 1927 ; Correspondance du Maréchal Valée (1839), 1954. 


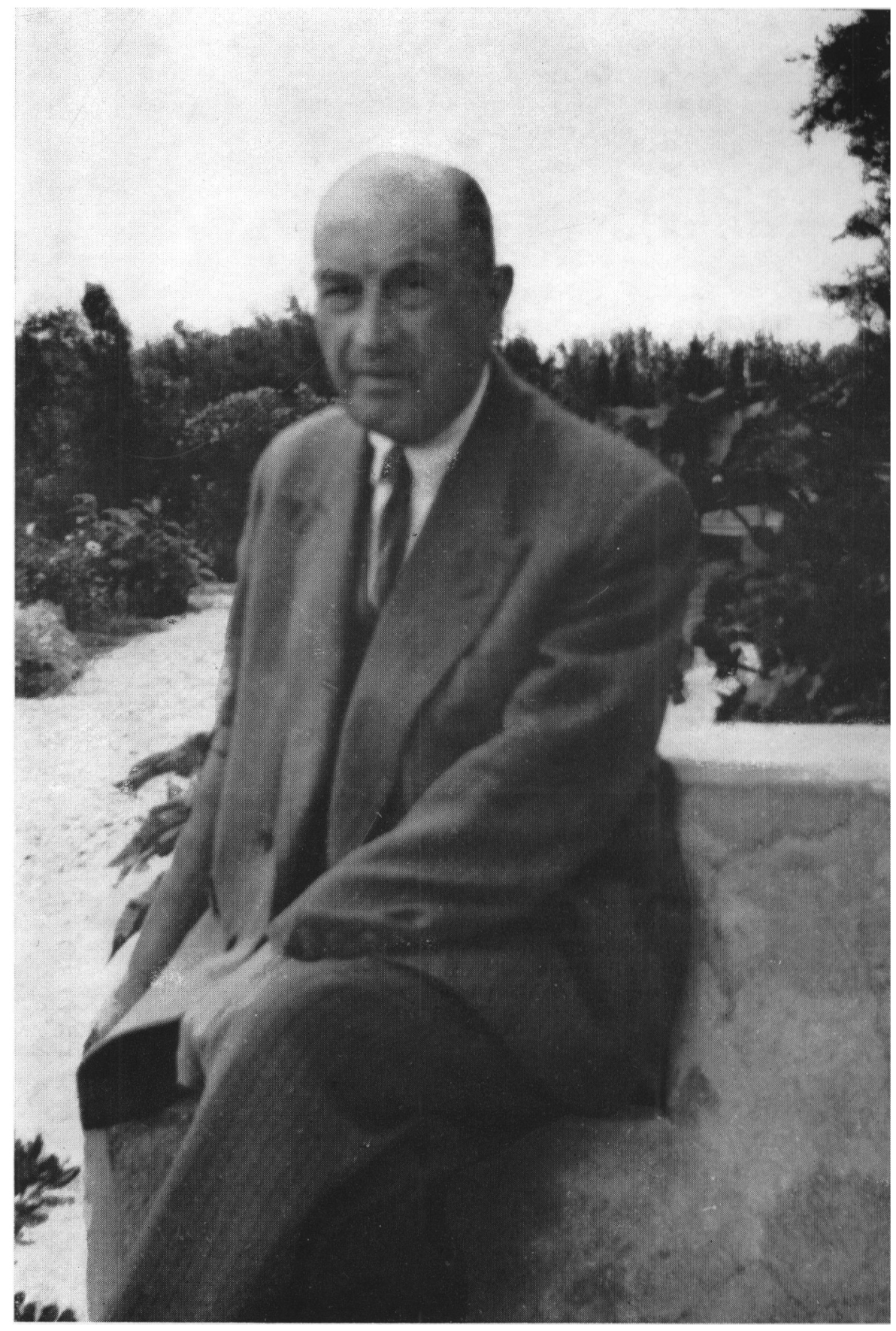

